\title{
Current and evolving treatment strategies in adult immune thrombocytopenia
}

\author{
Jan-Paul Bohn (D) Michael Steurer
}

Received: 31 May 2018 / Accepted: 1 August 2018 / Published online: 15 August 2018

(C) The Author(s) 2018

\begin{abstract}
Summary Immune thrombocytopenia (ITP) is an acquired autoimmune phenomenon resulting in low platelet count and increased bleeding risk. Goals of upfront management include prompt control of severe bleeding-which is rare-as well as induction and maintenance of a hemostatic platelet count. Thus, optimal management of ITP patients is often challenging and requires a highly individualized approach. Many patients may not suffer significant bleeding despite severe thrombocytopenia and the risk of toxicity associated with treatment may outweigh its benefit. Most patients treated with standard first-line regimen of glucocorticoids achieve an initial response. However, the rate of long-term remission remains low and multiple lines of therapy are often required. Current investigations aim at defining the subgroup of patients at risk of relapse and providing intensified risk-balanced induction regimens to improve long-term disease control.

This short review summarizes current and emerging treatment strategies in adult ITP.
\end{abstract}

Keywords Dexamethasone · Rituximab • Romiplostim $\cdot$ Eltrombopag $\cdot$ Splenectomy

Immune thrombocytopenia (ITP) is an uncommon but distinct autoimmune-mediated condition defined by a platelet count $<100,000 / \mu \mathrm{L}$ due to accelerated platelet destruction and impaired thrombopoiesis.

J.-P. Bohn, M.D. $(\varangle) \cdot$ M. Steurer, M.D.

Department of Internal Medicine V, Medical University of Innsbruck, Anichstraße 35, 6020 Innsbruck, Austria Jan-Paul.Bohn@i-med.ac.at

M. Steurer, M.D.

Michael.Steurer@i-med.ac.at
The incidence of ITP is estimated to be between 1.9 and 6.4/100,000/year in children and approximately $3.3 / 100,000 /$ year in adults with a slight overall female predominance [1]. Its clinical course is characterized by a variable bleeding tendency and disturbed health-related quality of life (QoL). Front-line management aims at rapid control of severe bleeding and its prevention by providing hemostatic platelet counts. However, many patients with ITP do not experience significant bleeding despite severe thrombocytopenia.

Accordingly, the decision to treat ITP patients can be challenging because the risk of bleeding is difficult to estimate. There is no robust risk model predicting bleeding complications and patients may more likely experience treatment-related toxicities than severe bleeding [2, 3].

This short review aims to summarize current and evolving treatment strategies and discuss clinically relevant obstacles to overcome.

\section{Platelet count and bleeding risk}

Although more severe thrombocytopenia (e.g., platelet count $<10,000 / \mu \mathrm{L}$ ) is associated with a higher risk of bleeding, the degree of thrombocytopenia does not strictly correlate with bleeding symptoms.

Even at platelet counts $<30,000 / \mu \mathrm{L}$ the link between platelet count and bleeding risk is weak. Bleeding events are the result of various risk factors and remain unpredictable with currently available laboratory analysis as they may also occur at higher platelet counts [2, 3]. Consequently, ITP is a very heterogeneous disease. Lacking an evidence-based threshold for what constitutes a safe platelet count, the American Society of Hematology recommends treatment for patients with a platelet count $<30,000 / \mu \mathrm{L}$ even in the absence of significant bleeding symptoms. Other guidelines merely recommend not to treat at 
Table 1 Platelet count responses to first-line treatment with high-dose dexamethasone in selected randomized controlled trials in adults with newly diagnosed immune thrombocytopenia (ITP)

\begin{tabular}{|c|c|c|c|c|c|c|c|c|}
\hline \multirow{3}{*}{$\begin{array}{l}\text { Trial } \\
\text { Wei et al. [11] }\end{array}$} & \multirow{2}{*}{$\begin{array}{l}\text { Regimen } \\
\text { Dexamethasone } 40 \mathrm{mg} / \text { day } \\
\text { d1-4× } 1-2 \text { cycles }\end{array}$} & \multirow{2}{*}{$\begin{array}{l}n \\
95\end{array}$} & \multicolumn{2}{|c|}{ Median time to response } & \multicolumn{2}{|c|}{ CRR at 3 months } & \multicolumn{2}{|c|}{ ORR at 6 months } \\
\hline & & & 3 months & $p<0.01$ & $48 \%$ & $p<0.01$ & $40 \%$ & $p>0.05$ \\
\hline & Prednisone $1 \mathrm{mg} / \mathrm{kg} / \mathrm{day} \times 4$ weeks & 97 & 6 months & & $26 \%$ & & $41 \%$ & \\
\hline \multirow[t]{2}{*}{ Bae et al. [12] } & $\begin{array}{l}\text { Dexamethasone } 40 \mathrm{mg} / \mathrm{day} \mathrm{d} 1-4 \times 1 \mathrm{cy}- \\
\text { cle }\end{array}$ & 76 & - & & - & & $25 \%$ & $p>0.05$ \\
\hline & Prednisone $1 \mathrm{mg} / \mathrm{kg} / \mathrm{day} \times 4$ weeks & 75 & - & & - & & $36 \%$ & \\
\hline
\end{tabular}

Table 2 Response to first-line treatment with high-dose dexamethasone and rituximab in selected randomized controlled trials in adults with newly diagnosed immune thrombocytopenia (ITP)

\begin{tabular}{|c|c|c|c|c|c|c|}
\hline \multirow{2}{*}{$\begin{array}{l}\text { Trial } \\
\text { Zaja et al. [15] }\end{array}$} & \multirow{2}{*}{$\begin{array}{l}\text { Regimen } \\
\text { Dexamethasone } 40 \mathrm{mg} / \text { day d1-4 } \times 1 \text { cycle } \\
\text { plus rituximab } 375 \mathrm{mg} / \mathrm{m}^{2} \text { weekly } \times 4\end{array}$} & \multirow{2}{*}{$\begin{array}{l}n \\
49\end{array}$} & \multicolumn{2}{|c|}{ ORR at 6 months } & \multicolumn{2}{|c|}{ Grade $3 / 4$ adverse events } \\
\hline & & & $63 \%$ & $p=0.04$ & $10 \%$ & $p=0.08$ \\
\hline & Dexamethasone $40 \mathrm{mg} / \mathrm{day} \mathrm{d} 1-4 \times 1$ cycle & 52 & $36 \%$ & & $2 \%$ & \\
\hline \multirow[t]{2}{*}{ Gudbrandsdottir et al. [16] } & $\begin{array}{l}\text { Dexamethasone } 40 \mathrm{mg} / \mathrm{day} \text { d } 1-4 \leq 6 \text { cycles } \\
\text { plus rituximab } 375 \mathrm{mg} / \mathrm{m}^{2} \text { weekly } \times 4\end{array}$ & 62 & $58 \%$ & \multirow[t]{2}{*}{$p=0.02$} & $26 \%$ & \multirow[t]{2}{*}{$p=0.04$} \\
\hline & Dexamethasone $40 \mathrm{mg} / \mathrm{d} d 1-4 \leq 6$ cycles & 71 & $37 \%$ & & $11 \%$ & \\
\hline
\end{tabular}

platelet counts $>50,000 / \mu \mathrm{L}$ [4]. Most patients with stable platelet counts $>30,000 / \mu \mathrm{L}$ and no significant bleeds do not require ITP-specific treatment. The risk of toxicity associated with treatment may outweigh its benefit in otherwise asymptomatic patients with mild to moderate thrombocytopenia and a very low bleeding tendency. Thus, the occurrence of bleeding symptoms and the overall background bleeding risk are critical determinants for treatment decisions requiring a highly individualized approach rather than strict platelet thresholds for the initiation of treatment.

\section{Fatigue and health-related QoL}

Platelet count alone does not adequately reflect the natural history of ITP and response to treatment. Although incompletely understood, fatigue in patients with ITP has been shown to be worse compared to the general population across several studies [5]. Multiple factors may contribute, such as immune alterations, fear of bleeding, restriction in daily activity, comorbidities as well as treatment-related side effects [6]. As such, health-related QoL, strongly affected by fatigue, can serve as an additional tool for evaluation of daily well-being. It has been demonstrated that the health-related QoL of ITP patients is not only worse than that of the general U.S. population but also of patients with arterial hypertension, arthritis, or cancer [7]. Whereas early ITP studies used rather general QoL questionnaires (e.g., EQ-5D, SF-36) a more disease-specific tool, the 50-item ITP Patient Assessment Questionnaire (ITP-PAQ) was successfully introduced, which can be applied to describe QoL changes over time in a treatment group [8]. Nevertheless, the effect of medications on QoL is understudied, and greater emphasis should be given to this topic in future trials.

\section{First-line treatment}

Oral corticosteroids (prednisolone $1-2 \mathrm{mg} / \mathrm{kg}$ per day over 2-4 weeks with a 4-6 week taper) have traditionally been the standard first-line treatment in adults with initial response rates between 60 and $80 \%$. However, relapses after drug tapering are frequent, occurring in $70-80 \%$ of patients [9].

As a result, investigators are currently evaluating whether intensification of up-front therapy with highdose dexamethasone and rituximab may enhance long-term outcome.

Emerging data favors shorter courses of high-dose dexamethasone ( $40 \mathrm{mg}$ orally per day for 4 consecutive days with no taper in repeated cycles every $2-4$ weeks) compared to prednisolone.

In a meta-analysis of nine randomized trials (1138 patients) evaluating outcomes for different glucocorticoid regimens, dexamethasone was associated with a higher overall response at 2 weeks (79 versus $59 \%$ ), deeper response at 2 weeks (complete response 64 versus $36 \%$ ), and fewer bleeding manifestations within the first 10 days (12 versus $24 \%$ ). Notably, dexamethasone was associated with fewer toxicities (24 versus 46 adverse events per 100 patients) [10].

Long-term response rate analysed at 6 months may not be enhanced by one or two cycles of high-dose dexamethasone compared to prednisolone (Table 1; $[11,12])$. Early evidence, however, suggests superiority when given for at least three cycles [13].

Rituximab is an anti-CD20 monoclonal antibody approved for malignant B-cell lymphomas and used in numerous autoimmune conditions [14]. Typical 
Table 3 Platelet count response to thrombopoietin receptor agonists in selected patients with chronic ITP

\begin{tabular}{|c|c|c|c|c|c|c|c|}
\hline Study & Regimen & $n$ & $\begin{array}{l}\text { Median time to re- } \\
\text { sponse }\end{array}$ & ORR & CRR & Sustained ORR ${ }^{\mathrm{a}}$ & $\begin{array}{l}\text { Median time of re- } \\
\text { sponse }\end{array}$ \\
\hline $\begin{array}{l}\text { Gonzalez-Lopez et al. } \\
\text { [24] }\end{array}$ & Eltrombopag $50 \mathrm{mg}$ daily & 164 & 12 days & $89 \%$ & $80 \%$ & $\begin{array}{l}75 \% \text { at } \\
15 \text { months }\end{array}$ & - \\
\hline \multirow[t]{2}{*}{ Mazza et al. [25] } & $\begin{array}{l}\text { Romiplostim } 1-10 \mu \mathrm{g} / \mathrm{kg} \mathrm{s.c.} \\
\text { weekly }\end{array}$ & 55 & 4 weeks & $80 \%$ & $44 \%$ & - & 30 months $^{c}$ \\
\hline & Eltrombopag $50 \mathrm{mg}$ p. 0 . daily & 69 & 4.5 weeks & $94 \%$ & $48 \%$ & - & 15 months $^{\mathrm{c}}$ \\
\hline
\end{tabular}

ITP immune thrombocytopenia, ORR overall response rate defined as platelet count $\geq 30,000 / \mu \mathrm{L}$, CRR complete response rate defined as platelet count $\geq 100,000 / \mu \mathrm{L}$, p.o. per os, s.c. subcutaneously

aifference in duration of response likely due to later onset of treatment with eltrombopag due to later drug availability

dosing in ITP is adopted from lymphoma treatments (4 infusions in weekly intervals at $375 \mathrm{mg} / \mathrm{m}^{2}$ ). Lower fixed doses (e.g., $100 \mathrm{mg}$ ) may also be sufficient to achieve a platelet count response, but ideal dosing in patients with ITP remains unclear [15].

Two randomized trials have evaluated the addition of rituximab to high-dose dexamethasone in patients with newly diagnosed ITP (236 patients). Response rates at 6 ( 63 vs $36 \%, n=103$ and 58 vs. $37 \%, n=133$ ) and 12 months (53 vs. $33 \%$; $n=133$ ) were significantly enhanced in the combination therapy arms at the cost of more frequent grade 3 and 4 adverse events (Table 2). As such, longer follow-up is needed to determine whether greater long-term response justifies greater toxicity $[16,17]$. Combination therapy with high-dose dexamethasone and rituximab is currently not recommended in newly diagnosed ITP outside of a clinical trial.

Intravenous immunoglobulin (IVIg) is typically administered at $1 \mathrm{~g} / \mathrm{kg}$ for one to two days, depending on when a response occurs. Its effect is generally transient but raises the platelet count more rapidly than glucocorticoids within 24 to $48 \mathrm{~h}$ [18]. IVIg is usually reserved for patients with severe bleeding, as preparation for patients in need for an urgent invasive procedure and/or bridging to more definitive second-line treatment in patients refractory to glucocorticoids. As a result, it is considered more of a rescue option in ITP than routine therapy.

Whether first-line treatment enhances health-related QoL remains to be elucidated in the absence of randomized controlled clinical trials addressing this issue.

\section{Second-line treatment}

As far as second-line therapy is concerned, splenectomy has been the treatment of choice for the last six decades. Two out of three patients achieve remission after splenectomy and long-term response rate is approximately $60 \%$ at 5-10 years [19]. Recently, however, the advent of rituximab and thrombopoietin receptor agonists (TRA) led to a decline in splenectomy [20]. Whether efficacy and safety of these newer agents is comparable with splenectomy is currently subject to investigation.
Efficacy profile seems favorable for a single course of rituximab with initial overall response and complete response rates of $55-75 \%$ and $40-60 \%$, respectively. However, this may not be followed by longterm remission given inferior sustained response rates of $20-40 \%$ at 2 years, and about $20 \%$ at 5 years [21].

So far, rituximab does not appear to improve health-related QoL as measured by ITP-PAQ or SF-36 [22].

TRA stimulate the production of megakaryocytes and ultimately platelets by binding to and activating the thrombopoietin receptor. Two TRA, romiplostim and eltrombopag, are currently licensed for adults with chronic ITP and achieve a remission in over $80 \%$ of patients [23].

Dosing of romiplostim ranges from 1 to $10 \mu \mathrm{g} / \mathrm{kg}$ administered as a once weekly subcutaneous injection and adjusted to maintain a platelet count $>50,000 / \mu \mathrm{L}$.

Eltrombopag is given as a once-daily pill at varying doses (typically $50 \mathrm{mg}$ ) to establish a platelet count of $>50,000 / \mu \mathrm{L}$.

When given continuously, over $90 \%$ of responding patients maintain their responses, typically at a stable dose (Table 3) [24, 25]. Single case series also highlight that a significant proportion of patients may experience sustained responses despite treatment discontinuation after 1 or 2 years [26, 27]. Cross-resistance has yet not been observed, meaning that patients unresponsive to one agent may benefit from the other [28].

Furthermore, TRA were demonstrated to enhance health-related QoL as measured by ITP-PAQ and SF36 [29, 30].

Safety of both agents is comparable with discontinuation of therapy due to adverse drug reactions in approximately $5-7 \%$ of patients $[27,30]$.

Besides hepatotoxicity associated with eltrombopag, suspected toxicities of TRA include thrombosis and bone marrow fibrosis. The incidence of thromboembolic complications, however, was demonstrated not to be significantly increased in a metaanalysis of 14 trials (921 patients) [31]. Whether TRA are associated with significant increase in reticulin and collagen fibrosis currently remains unclear.

Optimal treatment for patients in need of secondline therapy is still under debate. Some physicians favor splenectomy in the absence of a contraindication 


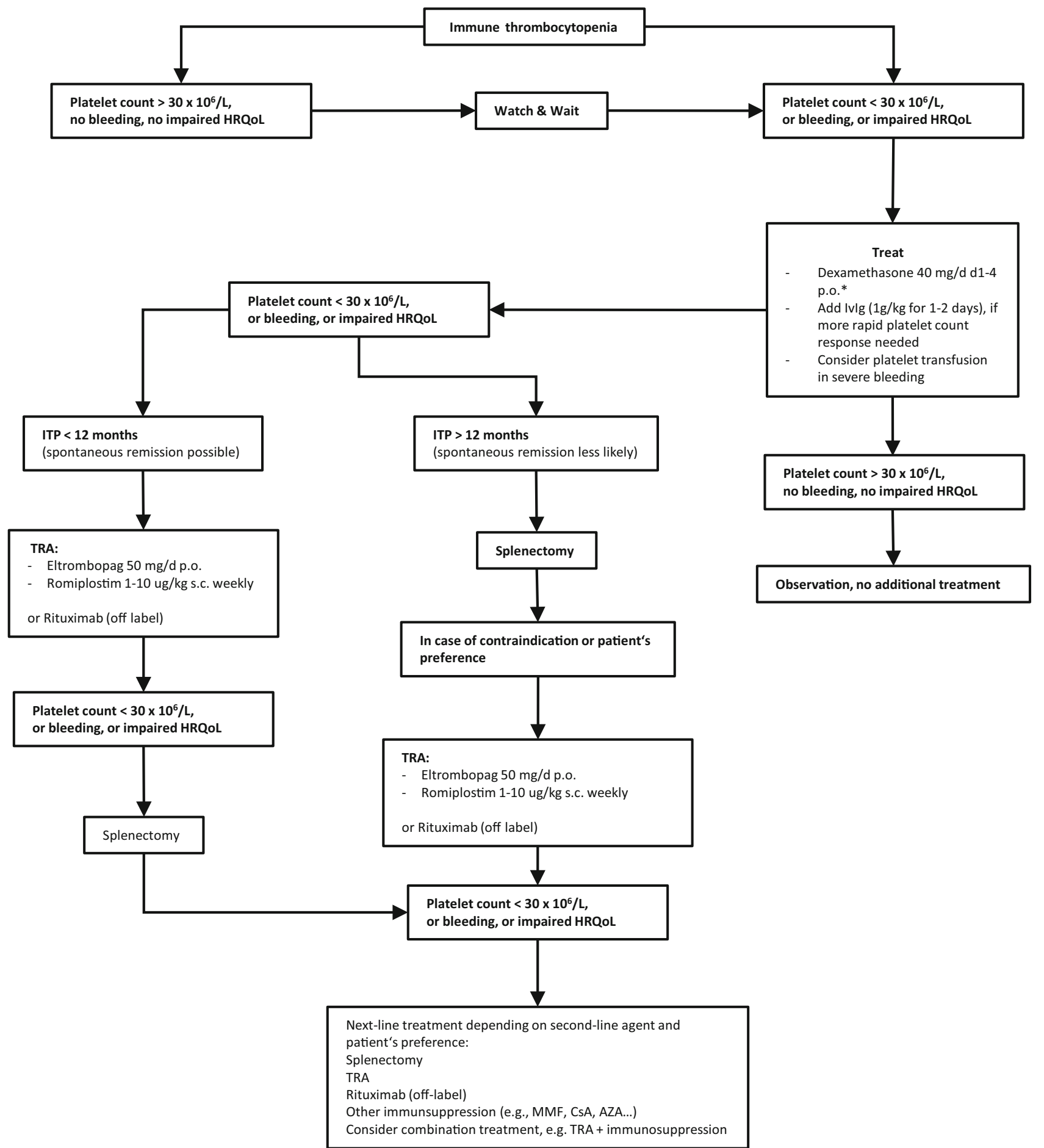

Fig. 1 Treatment algorithm in adult immune thrombocytopenia. ITP immune thrombocytopenia, Ivlg intravenous immunglobuline, TRA thrombopoietin receptor agonist, MMF mycophenolate mofetil, CSA cyclosporine A, AZA azathioprine,

to surgery. Others underline missing evidence necessary for prioritization among available therapeutic options.

Typically, the choice of second-line therapy is discussed with the patients balancing the pros and cons
HRQoL health-releated quality of life, p.o. per os, s.c. subcutaneously, $d$ day, ${ }^{*}$ alternatively prednisolone $1-2 \mathrm{mg} / \mathrm{kg}$ per day over several weeks with a 4-6 week taper

of each option in the context of their individual comorbidities and preferences.

The only absolute contraindications of splenectomy are uncontrolled coagulopathy and severe cardiovascular disease prohibiting or severely compromising general anesthesia. 
Fig. 1 provides an overview of current management strategies in adult ITP.

\section{Conclusion}

Most adults with ITP will eventually maintain a safe platelet count. The likelihood of long-term remission after standard corticosteroids, however, remains low even with intensified first-line treatment. Frequently, more than one line of therapy is required until a stable and durable response is achieved, mostly as a result of chronic treatment with TRA or splenectomy.

In this respect, it is crucial to investigate whether available drugs administered in novel combinations with corticosteroids, monoclonal antibodies or immunosuppressants can prevent relapse. Notably, adequate long-term follow-up including appropriate health-related QoL assessment is necessary to address this question in randomized controlled trials. Furthermore, it is critical to identify the subgroup of patients most at risk for developing chronic ITP and, thus, who would benefit from more intensive up-front treatment. This way, patients may be offered tailored therapies balancing between providing a safe and sustained platelet response and avoiding unnecessary treatment-related toxicities.

Funding Open access funding provided by University of Innsbruck and Medical University of Innsbruck.

Conflict of interest J.-P. Bohn and M. Steurer declare that they have no competing interests.

Open Access This article is distributed under the terms of the Creative Commons Attribution 4.0 International License (http://creativecommons.org/licenses/by/4.0/), which permits unrestricted use, distribution, and reproduction in any medium, provided you give appropriate credit to the original author(s) and the source, provide a link to the Creative Commons license, and indicate if changes were made.

\section{References}

1. Terrell DR, Beebe LA, Vesely SK, Neas BR, Segal JB, George JN. The incidence of immune thrombocytopenic purpura in children and adults: A critical review of published reports. Am J Hematol. 2010;180:85-174.

2. Neunert C, Noroozi N, Norman G, et al. Severe bleeding events in adults and children with primary immune thrombocytopenia: a systematic review. J Thromb Haemost. 2015;13:457-64.

3. ArnoldDM.Platelet count or bleeding as the outcomein ITP trials? Am J Hematol. 2012;87:945-6.

4. Provan D, Stasi R, Newland AC, et al. International consensus report on the investigation and management of primary immune thrombocytopenia. Blood. 2010;115:168-86.

5. Signorovitch J, Brainsky A, Grotzinger KM. Validation of the FACIT-fatigue subscale, selected items from FACT-thrombocytopenia, and the SF-36v2 in patients with chronic immune thrombocytopenia. Qual Life Res. 2011;20:1737-44.

6. Hill QA, Newland AC. Fatigue in immune thrombocytopenia. BrJ Haematol. 2015;170:141-9.
7. McMillan R, Bussel JB, George JN, et al. Self-reported health-related quality of life in adults with chronic immune thrombocytopenic purpura. Am J Hematol. 2008;83:150-4.

8. Mathias SD, Bussel JB, George JN, et al. A disease-specific measure of health-related quality of life for use in adults with immune thrombocytopenic purpura: its development and validation. Health Qual Life Outcomes. 2007;5:11.

9. Neunert CE, Buchanan GR, Imbach P, et al. Severe hemorrhage in children with newly diagnosed immune thrombocytopenic purpura. Blood. 2008;112:4003-8.

10. Mithoowani S, Gregory-Miller K, Goy J, et al. High-dose dexamethasone compared with prednisone for previously untreated primary immune thrombocytopenia: a systematic review and meta-analysis. Lancet Haematol. 2016;3:e489-e96.

11. Wei Y, Ji XB, Wang YW, et al. High-dose dexamethasone vs prednisone for treatment of adult immune thrombocytopenia: aprospectivemulticenter randomized trial. Blood. 2016;127:296-302. quiz370.

12. Bae SH, Ryoo H, Lee WS, Joo YD, Lee KH, Lee J, et al. High Dose dexamethasone Vs. Conventional Dose Prednisolone for Adults with Immune Thrombocytopenia: a Prospective Multicenter Phase III Trial. Blood. 2010;116:3687.

13. Din B, Wang X, Shi Y, Li Y. Long-term effect of high-dose dexamethasone with or without low-dose dexamethasone maintenance in untreated immune thrombocytopenia. Acta Haematol. 2015;133:124-8.

14. Anderson DR, Grillo-Lopez A, Varns C, et al. Targeted anticancer therapy using rituximab, a chimaeric anti-CD20 antibody (IDEC-C2B8) in the treatment of non-Hodgkin's B-cell lymphoma. Biochem Soc Trans. 1997;25:705-8.

15. Zaja F, Vianelli N, Volpetti S, et al. Low-dose rituximab in adult patients with primary immune thrombocytopenia. EurJ Haematol. 2010;85:329-34.

16. Gudbrandsdottir S, Birgens HS, Frederiksen H, et al. Rituximab and dexamethasonevs dexamethasone monotherapy in newly diagnosed patients with primary immune thrombocytopenia. Blood. 2013;121:1976-81.

17. Zaja F, Baccarani M, Mazza P, et al. Dexamethasone plus rituximab yields higher sustained response rates than dexamethasone monotherapy in adults with primary immune thrombocytopenia. Blood. 2010;115:2755-62.

18. Godeau B, Caulier MT, Decuypere L, et al. Intravenous immunoglobulin for adults with autoimmune thrombocytopenic purpura: results of a randomized trial comparing 0.5 and $1 \mathrm{~g} / \mathrm{kg}$ b.w. Br J Haematol. 1999;107:716-9.

19. Mikhael J, Northridge K, Lindquist K, et al. Short-term and long-term failure of laparoscopic splenectomy in adult immune thrombocytopenic purpura patients: a systematic review. Am J Hematol. 2009;84:743-8.

20. Palandri F, Polverelli N, Sollazzo D, et al. Have splenectomy rate and main outcomes of ITP changed after the introduction of new treatments? A monocentric study in the outpatient setting during 35 years. Am J Hematol. 2016;91:E267-E72.

21. Chugh S, Darvish-Kazem S, Lim W, et al. Rituximab plus standard of care for treatment of primary immune thrombocytopenia: a systematic review and meta-analysis. Lancet Haematol. 2015;2:e75-e81.

22. Arnold DM, Heddle NM, Carruthers J, et al. A pilot randomized trial of adjuvant rituximab or placebo for nonsplenectomized patients with immune thrombocytopenia. Blood. 2012;119:1356-62.

23. Weiss L, Greil R. Short review-Management of Immune Thrombocytopenia in adults. memo-Magazine of European. Med Oncol. 2010;3:69-72. 


\section{short review}

24. Gonzalez-Lopez TJ, Alvarez-Roman MT, Pascual C, et al. Eltrombopag safety and efficacy for primary chronic immune thrombocytopenia in clinical practice. Eur J Haematol. 2016;97:297-302.

25. Mazza P, Minoia C, Melpignano A, et al. The use of thrombopoietin-receptor agonists (TPO-RAs) in immune thrombocytopenia (ITP): a "real life" retrospective multicenter experience of the Rete Ematologica Pugliese (REP). Ann Hematol. 2016;95:239-44.

26. Gonzalez-Lopez TJ, Pascual C, Alvarez-Roman MT, et al. Successful discontinuation of eltrombopag after complete remission in patients with primary immune thrombocytopenia. Am J Hematol. 2015;90:E40-E3.

27. SteurerM,QuittetP,PapadakiHA, etal. Alargeobservational study of patients with primary immune thrombocytopenia receiving romiplostim in European clinical practice. Eur J Haematol. 2017;98:112-20.

28. Gonzalez-Porras JR, Mingot-Castellano ME, Andrade MM, et al. Use of eltrombopag after romiplostim in primary immune thrombocytopenia. Br JHaematol. 2015;169:111-6.

29. George JN, Mathias SD, Go RS, et al. Improved quality of life for romiplostim-treated patients with chronic immune thrombocytopenic purpura: results from two randomized, placebo-controlled trials. Br J Haematol. 2009;144:409-15.

30. Bussel JB, Provan D, Shamsi T, et al. Effect of eltrombopag on platelet counts and bleeding during treatment of chronic idiopathic thrombocytopenic purpura: a randomised, double-blind, placebo-controlled trial. Lancet. 2009;373:641-8.

31. Cines DB, Gernsheimer T, Wasser J, et al. Integrated analysis of long-term safety in patients with chronic immune thrombocytopaenia (ITP) treated with the thrombopoietin (TPO) receptor agonist romiplostim. Int J Hematol. 2015;102:259-70.

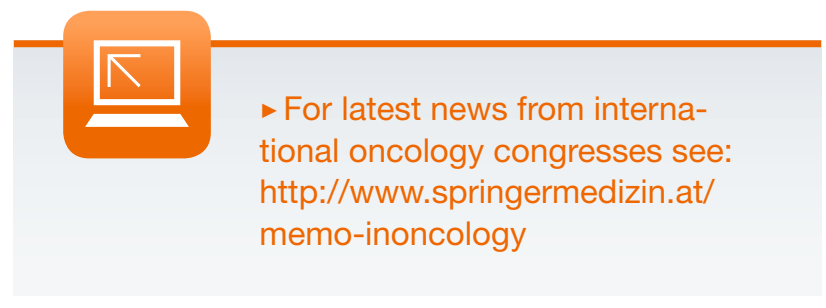

